\title{
Hydrophilic CO-releasing material of PEGlyated Ruthenium Carbonyl Complex
}

\author{
Xiao Zhang ${ }^{1}$, Nan Guo ${ }^{2}$, Shuhong Yang ${ }^{1}$, Huma Khan ${ }^{1}$ and Weiqiang Zhang ${ }^{1, *}$ \\ 1 Key Laboratory of Applied Surface and Colloid Chemistry MOE, School of Chemistry and Chemical \\ Engineering, Shaanxi Normal University, Xi'an 710062, China; zX@snnu.edu.cn(X.Z.); 917501881@qq.com(S.Y.); \\ huma7662@gmail.com(H.K.) \\ 2 Northwest University, Xi'an 710127, China; 13991393343@163.com(N.G.) \\ * Correspondence: mailto:zwq@snnu.edu.cn; Tel.: +86-181-8243-8818 (W.Z.)
}

\begin{abstract}
The poor water-solubility and instability of $\mathrm{Ru}(\mathrm{II})$ carbonyl complex hamper the therapeutic application as $\mathrm{CO}$ releasing materials (CO-RMs). To enhance the hydrophilicity and bio-utility of $\mathrm{CO}$, a robust $\mathrm{Ru}(\mathrm{I})$ carbonyl sawhorse skeleton were grafted with water-soluble PEGlyated sidearms. Twelve PEGlyted sawhorse $\mathrm{Ru}_{2}(\mathrm{CO})_{4}$ complexes were prepared with satisfactory yields and characterized by IR and ${ }^{1} \mathrm{H}$ - and ${ }^{13} \mathrm{C}$ - NMR. X-ray diffraction analysis of CO-RM 8, 13 and 14 revealed the featured diruthenium sawhorse skeleton and PEGylated axial ligands. The flask-shaking method measures the hydrophilicity of CO-RMs, indicating that both bridging carboxylate ligand and PEGlyated axial ligands regulate the hydrophilicity of these CO-RMs. Under photolysis conditions, CO-RM 4-13 sustainable released therapeutic amounts of CO in myoglobin assay. The correlation of the $\mathrm{CO}$ release kinetics and hydrophilicity of CO-RMs demonstrated that the more hydrophilic CO-RM released CO faster. The biological test found the low cytotoxic CO-RM 4 showed a specific anticancer activity toward HT-29 tumour cells.
\end{abstract}

Keywords: Ruthenium complex; Carbon monoxide releasing molecule; Hydrophilicity, PEGylation.

\section{Introduction}

Recently, biologic experiments using transition metal carbonyl complexes as CO-Releasing molecule (CO-RM) [1] revealed the therapeutic effects of endogenous CO. These effects include anti-inflammatory function, vasodilatation, anti-apoptotic, anti-proliferative, and anti-hypoxia [2]. The organ protection of $\mathrm{CO}$ is desirable attractive because controlling a low concentration of $\mathrm{CO}$ indeed protects donor tissues from ischaemia-reperfusion injury [3]. The ruthenium carbonyl complex, $\left[\mathrm{Ru}(\mathrm{CO})_{3} \mathrm{Cl}_{2}\right]_{2}, \mathrm{CO}-\mathrm{RM}-02$, mainly were fasinating because it attenuated acute hepatic ischemia-reperfusion injury in rats by reducing serum AST/ALT levels and improves the liver histology score [4]. However, the poor solubility of CO-RM-02 and its unregulated CO releasing property in aqueous systems hinder the therapeutic application under physiological conditions [5]. To solve the water-solubility issue, CO-RM-02 was solubilized in DMSO, which readily reacts with the CO-RM dimer to generate DMSO-ligated monomeric ruthenium carbonyl species [6]. Motterlini and Mann found that glycinate ligands chelate to Ru (II) carbonyl moiety, and the corresponding $\mathrm{Ru}$ (II) complex (CO-RM-03) were water- soluble. Unfortunately, CORM-03 degrades rapidly in the human plasma, and the half-life of CO release was only 3.6 minutes [7]. In fact, due to the intrinsic hydrophobic nature of $\mathrm{CO}$, most metal carbonyl complexes have minimal solubility in an aqueous solution. Although a few ionic transition metal carbonyl complexes are water-soluble, the $\mathrm{CO}$ release tests indicated that the $\mathrm{M}-\mathrm{CO}$ bonds of simple ionic CO-RM degraded quickly under complicated physiological conditions and produced unpredictable side effects, such as blocking blood vessels and causing cytotoxic effects. To increase the water-solubility and finely control the CO release kinetics of transition metal complexes are challenges in the design of therapeutic CO-RMs [8-12]. 


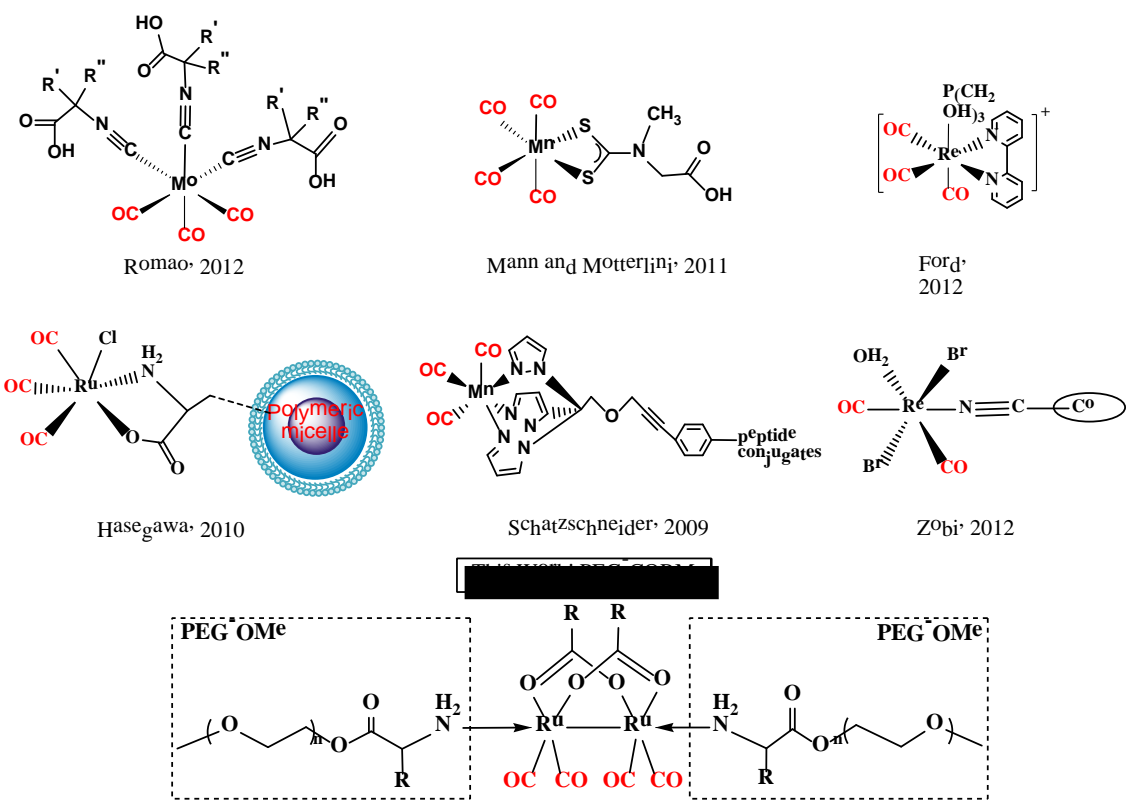

Scheme 1. Selected Water-soluble CO-RMs

Introducing the hydrophilic functional groups into the coordination sphere of transition metal complexes is an efficient way to enhance the water-solubility of the leading CO-RM structure (Scheme 1.). The hydrophilic auxiliary ligands bearing carboxylic acid groups improve the hydrophilicity of $\left(\mathrm{Mo}(\mathrm{CO})_{3}\left(\mathrm{CNCR}^{\prime} \mathrm{R}^{\prime \prime} \mathrm{CO}_{2} \mathrm{R}^{\prime \prime \prime}\right)_{3}\right.$ [13] and $\left[\mathrm{Mn}(\mathrm{CO})_{4}\left\{\mathrm{~S}_{2} \mathrm{CNMe}\left(\mathrm{CH}_{2} \mathrm{CO}_{2} \mathrm{H}\right)\right\}\right][14]$, respectively. The classic water-soluble phosphine ligand, $\mathrm{P}\left(\mathrm{CH}_{2} \mathrm{OH}\right)_{3}$ coordinates to $\mathrm{Ru}(\mathrm{I})$ center and significantly enhance the solubility of Photo-CO-RM, 2, 2'-bipyridine tricarbonyl rhenium(I) in PBS solution [15]. Conjugation of transition metal carbonyl moiety with the hydrophilic biomacromolecules also improves the water solubility and biocompatibility of CO-RMs. The micellar bearing $\left[\mathrm{RuCl}\right.$ (glycinate) $\left.(\mathrm{CO})_{3}\right][16]$, peptide conjugates of $\left[\mathrm{Mn}(\mathrm{CO})_{3}(\mathrm{tmp})\right]^{+}[17]$, and a photo-CORM based on vitaminB12, namely, B12-ReCO-RM2 [18] were fabricated to delivery CO in aqueous system. However, the synthesis and purification of these hydrophilic CO-RMs are sophisticated. More importantly, the $\mathrm{CO}$ release kinetics of most of the water-soluble CO-RMs are unpredictable and thus cannot satisfy the basic requirements of ADME proprieties for CO pre-drugs [19]. Polyethylene glycol (PEG) is a non-ionic polymer that improves water solubility and selective drug absorption. Inspired by the idea of PEG-polymer linking drug system proposed by $\mathrm{H}$. Ringsdorf [20], and the subsequent precedents of PEGlyated therapeutic agents by A. Abuchowski [21]. Herein, CO-RMs, which are PEGlylated Sawhorse Ru carbonyl complexes, were synthesized by incorporating a robust CO-RM lead structure $\left[\mathrm{Ru}_{2}(\mathrm{CO})_{4}(\mathrm{COOR})_{2}\right]$ with functionalized PEG chains. X-ray singlecrystal analysis revealed that the designed PEG esters of amino acids coordinate to $\mathrm{Ru}(\mathrm{I})$ of the sawhorse CO-RM lead structure. From the results of the $\log P$ measurements and myoglobin assay experiments, it was found that these hydrophilic CO-RMs show a wellcontrolled CO release property with broad kinetics under physiologic conditions.

\section{Results and Discussion}
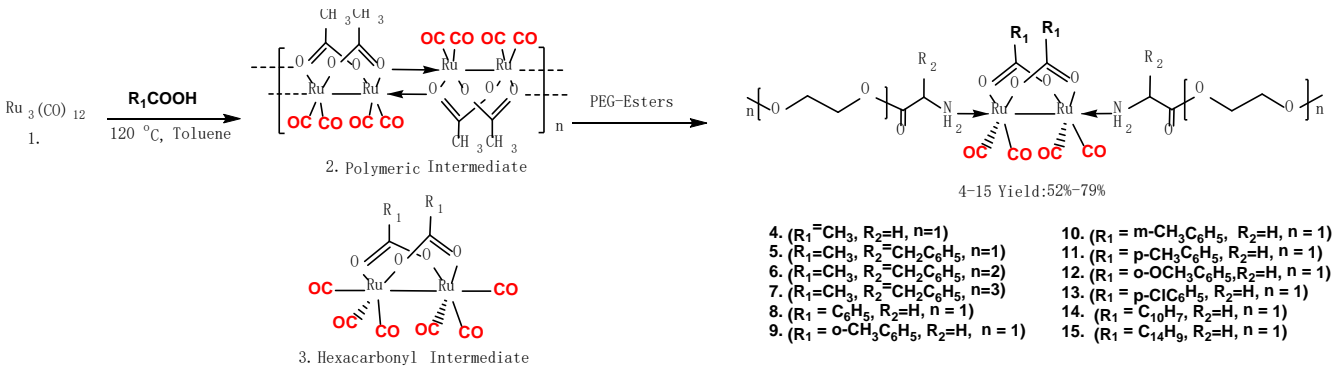

10. $\left(R_{1}=m-C_{3} C_{6} H_{5}, R_{2}=H, n=1\right)$ 11. $\left(R_{1}=p-\mathrm{CH}_{3} \mathrm{C}_{6} \mathrm{H}_{5}, \mathrm{R}_{2}=\mathrm{H}, \mathrm{n}=1\right)$
12. $\left(\mathrm{R}_{1}=\mathrm{O}-\mathrm{OCO} \mathrm{H}_{3} \mathrm{C}_{6} \mathrm{H}_{2}, \mathrm{R}_{2}=\mathrm{H}, \mathrm{n}=1\right)$ 13. $\left(R_{1}=\mathrm{o}-\mathrm{O}-\mathrm{ClC}_{6} \mathrm{H}_{5}, \mathbf{R}_{2}=\mathrm{H}, \mathrm{n}=1\right)$ 3. Hexacarbonyl Intermediate $\begin{array}{ll}\text { 8. }\left(R_{1}=C_{6} H_{5}, R_{2}=H, n=1\right) & \text { 14. }\left(R_{1}=C_{10} H_{7}, R_{2}=H, n=1\right) \\ \text { 9. }\left(R_{1}=0-C_{3} C_{6} H_{5}, R_{2}=H, n=1\right) & \text { 15. }\left(R_{1}=C_{14} H_{9}, R_{2}=H, n=1\right)\end{array}$

Scheme 2. PEGlyation of Sawhorse $\mathrm{Ru}_{2}(\mathrm{CO})_{4}$ complex of 4-15. 
Since 1969 when J. Lewis first reported $\mathrm{Ru}_{2}(\mathrm{CO})_{4}(\mathrm{O}(\mathrm{C}=\mathrm{O}) \mathrm{R})_{2} \mathrm{~L}_{2}$, features a sawhorse structure [22], a considerable number of the ruthenium(I) carbonyl complexes have been prepared and characterized. However, the inherited poor water-solubility and biological incompatibility of sawhorse ruthenium complexes are obstacles to its application in the biological system [23]. To increase the hydrophilicity of these ruthenium carbonyl complexes, the water-soluble amino acid glycol and PEG esters were tethered at the axial position of the sawhorse structure, respectively (Scheme 2). The thermolysis of Rus(CO)12 1 in acetic acids affords polymeric sawhorse ruthenium carbonyl $\mathbf{2}$, and the sequential ligand substitution reaction using glycine methyl esters flourishes the PEGylated sawhorse complexes 4-7 with 61-74\% yield. The light yellow products 4-7 are moisture and air-stable and easily manipulated without proof from oxygen or light. The thermolysis of $\mathrm{Ru}_{3}(\mathrm{CO})_{12}$ $\mathbf{1}$ and aromatic carboxylic acid at $120^{\circ} \mathrm{C}$ in toluene generates hexacarbonyl $\mathrm{Ru}(\mathrm{I})$ intermediates 2 and has the characteristic carbonyl bands at 2103w, 2079vs, 2035vs, 2004vs and $1938 \mathrm{w} \mathrm{cm}^{-1}$. The axial carbonyl ligands of 2 are labile and can readily be substituted by glycine esters of ethylene glycol monomethyl ester. Thermolysis using various bridged aromatic carboxylic acids afforded 8-15, and FT-IR, ${ }^{1} \mathrm{H}-\mathrm{NMR}$, mass spectrometry and elemental analysis were used to fully characterize complexes 4-15. The IR spectra of the $\mathrm{Ru}(\mathrm{I})$ complexes identified the four characteristic carbonyl bands at 2028-1938 $\mathrm{cm}^{-1}$ of sawhorse $\mathrm{Ru}_{2}(\mathrm{CO})_{4}$ complexes whilst the bridged-carboxylato ligand showed $\mathrm{C}=\mathrm{O}$ band at $1743 \mathrm{~cm}$ 1. The NMR spectra revealed more detailed information about the molecular structures of these ruthenium complexes with more details. In the ${ }^{1} \mathrm{H}-\mathrm{NMR}$ spectrum of 4 , the bridgedacetate was observed as a singlet at $\delta 1.94 \mathrm{ppm}$, and the protons of $\mathrm{NH}_{2}$ appeared as a singlet at $\delta 2.90 \mathrm{ppm} . \mathrm{CH}_{2}$ and $\mathrm{OCH}_{3}$ of axial ethylene glycol monomethyl ester glycine ester appeared as triplets at $\delta 4.35,3.75,3.62 \mathrm{ppm}$, and a singlet at $3.39 \mathrm{ppm}$, respectively. The ${ }^{13} \mathrm{C}\left\{{ }^{1} \mathrm{H}\right\}$ NMR spectrum of 4 shows three types of $\mathrm{CO}$ resonances, and the Ru bonded carbonyl groups are at $\delta 204 \mathrm{ppm}$, the bridging carboxlyate is at $\delta 172 \mathrm{ppm}$, and the ester group is at $\delta 184 \mathrm{ppm}$, respectively. 4-15 showed similar resonances for both bridged and axial ligands. Notably, the amino protons of $\mu_{2}$-acetato complex 4 appear at $\delta 2.90 \mathrm{ppm}$, lower than the corresponding chemical shift of $\mu$-arylcarboxylato complexes 8-15. The shielded amino proton of 4 reflects less electron donation to the sawhorse unite, indicating the corresponding axial ligand may be more liable.

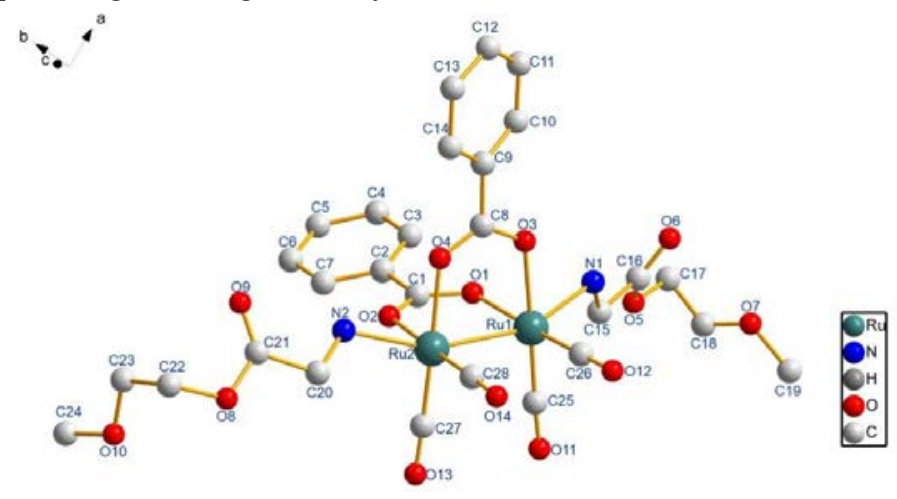

Fig. 1. Molecular structures of 8 ( $\mathrm{H}$ atoms are omitted for clarity).

Table 1. Selected Bond Distances $(\AA)$ and Angles (deg) for 8, 13 and 14

\begin{tabular}{|c|c|c|c|c|c|}
\hline Entry & Ru(1)-Ru(2) & Ru(1)-N(1) & Ru(2)-N(2) & $\mathrm{Ru}(1)-\mathrm{Ru}(2)-\mathrm{N}(2)$ & Ru(2)-Ru(1)-N(1) \\
\hline 8 & $2.6694(10)$ & $2.239(5)$ & $2.210(5)$ & $157.86(15)$ & $158.27(15)$ \\
\hline 13 & $2.6634(7)$ & $2.249(4)$ & $2.249(4)$ & 159.09(11) & $160.28(11)$ \\
\hline 14 & 2.6727(5) & $2.233(4)$ & $2.240(4)$ & 158.27(11) & 159.84(10) \\
\hline
\end{tabular}

Yellow crystals of three diruthenium (I) complexes 8, 13 and 14 were obtained via the diffusion of petroleum ether to $\mathrm{CH}_{2} \mathrm{Cl}_{2}$ solution of complexes at $0{ }^{\circ} \mathrm{C}$. Single crystal X-ray diffraction was used to characterize these complexes' molecular structures, and the results are shown in Table 1. The molecular structures feature a typical sawhorse structure that consists of a diruthenium tetracarbonyl core surrounded by two ethylene glycol monome- 
thyl ester glycine esters as axial ligands and two arylcarboxylato ligands at equatorial positions. Three crystals belong to the monoclinic system with the C2/c space group. The RuRu bond distances in these sawhorse skeletons are 2.6694(10) $\AA$ (8), 2.6634(7) $\AA$ (13) and 2.6727(5) $\AA$ (14), respectively; these values are with a metal-metal single bond[24]. The Ru$\mathrm{CO}$ bond length of each terminal carbonyl is slightly different. For instance, the average Ru-CO bond length of these complexes is about $1.83 \AA$, which is shorter than Ru-CO (1.943(3) $\AA$ and 1.903(3) $\AA$ ) of CO-RM-3 [7], but longer than Ru-CO(1.76 $\AA$ ) in those of axial triphenylphosphine analogues [24]. In complex 8, Ru(1)-N(1) 2.239(5) $\AA$ is slightly more than $\mathrm{Ru}(2)-\mathrm{N}(2) 2.210(5) \AA$, and the average $\mathrm{Ru}-\mathrm{Ru}-\mathrm{N}$ angle about $158^{\circ}$, indicating the former axial ligand might is more labile and readily dissociate during the $\mathrm{CO}$ releasing process. Interesting, in complex $13, \mathrm{Ru}(1)-\mathrm{N}(1)$ and $\mathrm{Ru}(2)-\mathrm{N}(2)$ have same distance at 2.249(4) $\AA$, but $\mathrm{Ru}(2)-\mathrm{Ru}(1)-\mathrm{N}(1)=160.28(11)^{\mathrm{o}}$ bigger than $\mathrm{Ru}(1)-\mathrm{Ru}(2)-\mathrm{N}(2)=159.09(11)^{\mathrm{o}}$.

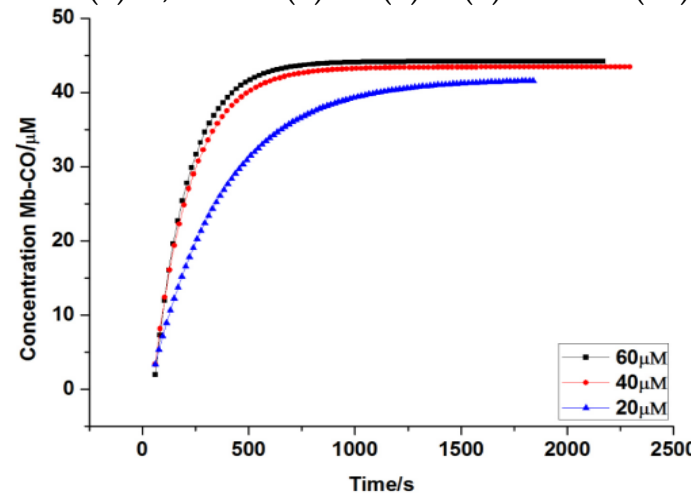

(a)

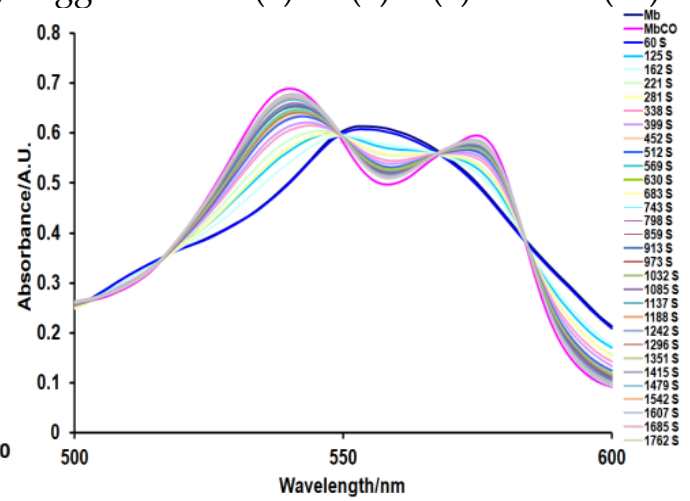

(b)

Fig. 2 Photo-activated CO release profile for 4 (a) UV-vis spectrum showing the Q-bands during the conversion of deoxy-Mb to Mb-CO with time while the concentration of CO-RMs is 60; (b) The CO-

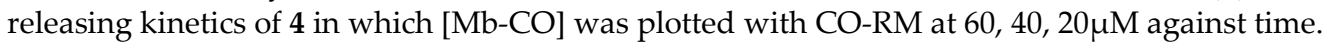

The CO release activity of each CO-RM in vivo was measured with the "golden standard" of myoglobin assay. Firstly, sodium dithionite was added to reduce myoglobin to deoxy-myoglobin (deoxyMb) in PBS $(\mathrm{pH}=7.4)$ at $37.8{ }^{\circ} \mathrm{C}$. A stock solution of CO-RM was added and then activated by LED-UV radiation at $365 \mathrm{~nm}$, releasing $\mathrm{CO}$ in vivo. The change of deoxyMb to carbonmonoxy-myogblobin $(\mathrm{MbCO})$ were monitored by UV-vis spectroscopy. A typical series of electronic absorption spectra (Fig. 3) showed the conversion of deoxyMb to $\mathrm{MbCO}$ in the presence of $\mathrm{CO}$ released from 4 . The half-lives of $\mathrm{CO}$ release rate of 4 at $60 \mu \mathrm{M}$ is $166 \mathrm{~s}, 40 \mu \mathrm{M}$ is $172 \mathrm{~s}$, and $20 \mu \mathrm{M}$ is $267 \mathrm{~s}$. Four isosbetic points demonstrated the biocompatibility of this CO-RM. The controlled CO release experiment in the dark showed that all CO-RMs are stable and do not spontaneously degrade at the physiological condition. Tuning the time and dense of UV radiation also control the kinetic of CO releasing from CO-RM whilst the molecular structures of CO-RMs determined their photo-sensitivity and $\mathrm{CO}$ release activity.

Table 2. The Correlation of Hydrophilicityand CO releasing kinetics of CO-RM

\begin{tabular}{ccc}
\hline CO-RM & $\log \mathbf{P}$ a & $\mathbf{t}_{1 / 2}, \mathbf{6 0} \boldsymbol{\mu} \mathbf{M}^{\mathbf{b}}$. \\
\hline 4 & 0.39 & 166 \\
5 & 1.41 & 276 \\
6 & 1.17 & 249 \\
7 & 1.05 & 189 \\
8 & 1.71 & 1209 \\
9 & 1.67 & 632 \\
10 & 1.03 & 962 \\
11 & 1.06 & 1096 \\
12 & 1.78 & 1450 \\
13 & 1.26 & 966 \\
14 & N. D. & 2699 \\
\hline
\end{tabular}

Note: [a] Oil-water partition coefficient by UV-vis.

[b] CO releasing Kinetics measured with myoglobin assay as t1/2, s. 
To identify the structural features of CO-RMs that govern the $\mathrm{CO}$ releasing behaviour, the $\mathrm{CO}$ release kinetics of 4-15 were correlated to the corresponding $\mathrm{M}-\mathrm{CO}$ band and lipophilicity in Table 3. Firstly, the oil-water partition coefficient log P values of complexes were measured by the "flask-shaking" method with n-octanol and water, respectively [25]. The $\log \mathrm{P}$ value of $\mathbf{4 - 1 3}$ ranges from 0.39 to 1.78 . The water-solubility of these sawhorse ruthenium copmlex mainly depends on both the axial glycol amino esters and bridging carboxylate, respectively. 4 exhibited the lowest $\log P$ value of 0.39 , which release $\mathrm{CO}$ fastest and convert 30um $\mathrm{Mb}$ to $\mathrm{MbCO}$ for just 163s using 60um CO-RM. The benzyl substitutes of axial glycol glycinate ester significantly reduce the hydrophilicity of 5 . The LogP value of 5 increased to 1.41 and the CO release half-life of $5 \mathrm{t}_{1 / 2}$, 60um decreased to 276s. The longer PEG chain of 6 and 7 enhanced the hydrophilicity of acetate bridging CORM. The higher LogP and faster CO release rate were observed (Table 2, CO-RM 6 and 7). The aromatic bridging ligands were utilized to finely tune the sawhorse structures. The substitutes on the arene are related to the hydrophilicity of aromatic carboxylate bridging CO-RM. 8, 9 and 12 showed higher LogP values as 1.71, 1.67 and 1.78, respectively, which released $\mathrm{CO}$ much slower with $\mathrm{t}_{1 / 2}, 60 \mathrm{um}$ around $1000 \mathrm{~s}$. Interestingly, The para-substituted methyl-, chloro- 10, 11 and meta methoxy-13 groups increase the hydrophilicity, and the corresponding CO rate of each aromatic CO-RM. 14 and 15 are too hydrophobic to be evaluated via the "flask-shaking" method, which $t_{1 / 2}, 60$ um is over 2000s. These experiments demonstrated that hydrophilicity is another factor controlling CO release in the aqueous system.

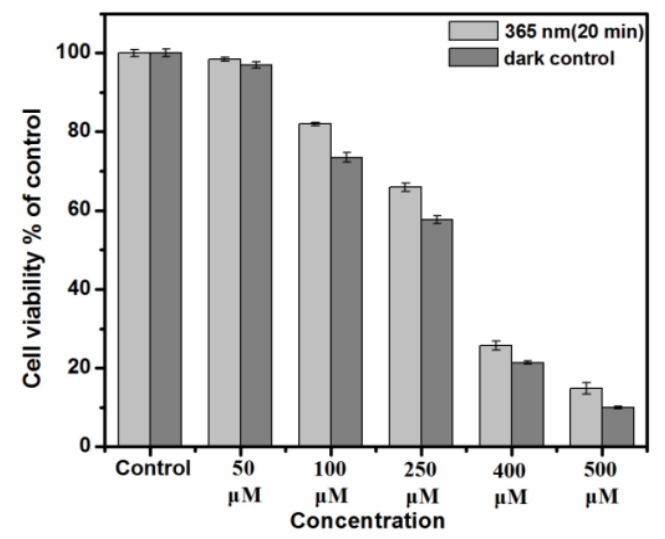

(a)

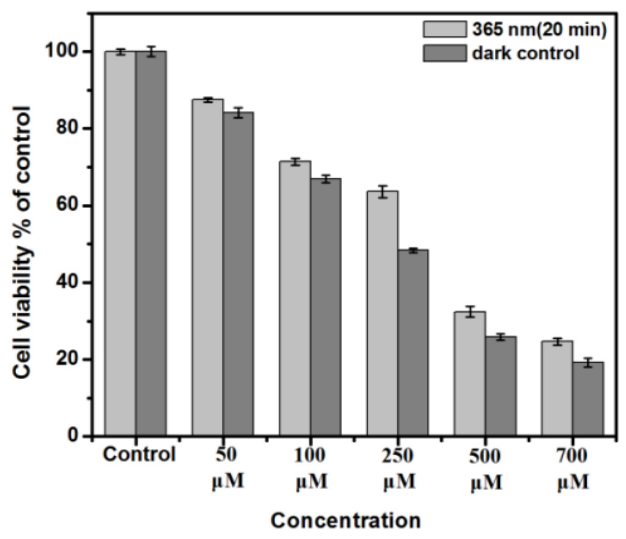

(b)

Fig. 4. Cell viability of RAW264.7 cell (a) and HT29 (b) in presence of 4. Cells were grown in the presence of $4(50-500 \mu \mathrm{M})$ and right in the dark (b) or Irradiated at $365 \mathrm{~nm}$ for $20 \mathrm{~min}$.

Each component of $\mathrm{CO}-\mathrm{RM}$, such as $\mathrm{Ru}$, carboxylic acid and amino acid esters, are known as less harmless than most of the other CO-RM, the cytotoxicity of CO-RM is still unknown. To predict the potential effect of CO-RM in vivo or on primary cells, the cytotoxicity of 4 were investigated with the popular murine macrophage cell line, RAW 264.7 and the human colon adenocarcinoma cell line HT29. Generally, IC50 of 4 over two cell lines showed less cytotoxicity in the dark, in constant with the cellular protection effect of endogenous CO. The MMT experiments showed that $100 \mu \mathrm{M}$ to $500 \mu \mathrm{M}$ of 4 significantly impacted the cell viability of RAW264.7 (Fig. 4a). $100 \mu \mathrm{M}$ of 4 started to reduce the cell survival rate. As the concentration of CO-RM increased, the survival rate of the cell dropped sharply. In the presence of 400uM and 500uM of 4, RAW264.7's survival rate was $22.3 \%$ and $10 \%$, respectively. The IC50 value is $253.3 \mu \mathrm{mol} / \mathrm{L}$, which showed that 4 was less toxic to RAW264.7 cells. The human colon adenocarcinoma cell line HT29, is not only used to study the biology of human colon cancers, but it is receiving special interest in studies focused on food digestion and bioavailability due to the ability to express characteristics of mature intestinal cells. To evaluate the potential of CO-RM for CO therapy as anti-cancer agents, the cytotoxicity of 4 over HT-29 were measured with the IC50 value of $300.3 \mu \mathrm{mol} / \mathrm{L}$. The further experiments with HT29 cells using the concentration of 4 in the range from $50 \mu \mathrm{M}$ to $700 \mu \mathrm{M}$ (Fig. 4 b). A concentration of 4 in $50 \mu \mathrm{M}, 12.5 \%$ of the cells 
lose activity in light stimulation. When the concentration increased to $700 \mu \mathrm{M}, \mathrm{HT} 29$ cells survived just $24.7 \%$. The IC50 value is $342.4 \mu \mathrm{mol} / \mathrm{L}$. Interestingly, 4 showed the similar anticancer activity in the dark, indicating the anticancer activity of 4 might result from CO-RM as a whole rather than its' released CO.

\section{Materials and Methods}

All manipulations were accomplished with standard Schlenk techniques. Decacarbonyl-ruthenium ( $\left.\mathrm{Ru}_{3}(\mathrm{CO})_{12}\right)$ and $\mathrm{mPEG}$ amino acid esters were prepared according to literature procedures [24].CO releasing test were performed using myogblin assay. The cytotoxicity and anticancer activity were measured with RAW264.7 and HTC-29 cells, respectively. The details of experiments were listed in ESI.

\section{Conclusions}

In conclusion, the robust sawhorse skeletons of the diruthenium carbonyl complex were devised with PEGlyated ligands to tune the CO releasing and bioavailability of CORMs. The myoglobin assay test on the CO releasing rate showed well-controlled release kinetics of CO-RMs 4-13 with $\mathrm{t}_{1 / 2}, 60 \mathrm{uM}$ from 166s to 2699s. The Log P values of CO-RMs were correlated with $\mathrm{CO}$ release rates, revealing the intrinsic relationship between the water-solubility and $\mathrm{CO}$ releasing activity of CO-RM. The CO-RMs with smaller LogP released $\mathrm{CO}$ faster, which might prove the concept of enhancing water-solubility to improve the release $\mathrm{CO}$ properties. The hydrophilicity of CO-RM was finely tuned via selecting carboxylate bridging ligands and glycol amino acid esters. MTT assay confirmed that CO-RM 4 consisted of acetate and glycol glycine ester as ligands were less cytotoxic to RAW264.7, but specificly toxic to HT29 cancer cells. These CO releasing and bioactivity experiments demonstrated the PEGylated Sawhorse ruthenium carbonyl complex's druglike properties and the promising therapeutic potentials.

Supplementary Materials: Figure S1, S2: Molecular structure of complex 13, 14, Table S1: Data Collection and Structural Refinements Details for Single-Crystal X-ray Diffraction Stud-ies of Complexes 8, 13 and 14.

Author Contributions: Conceptualization, W. Z. (Weiqiang Zhang); Methodology, X. Z. (Xiao Zhang), S. Y. (Shuhong Yang), N. G. (Nan Gao) and W.Z.; Writing - Original Draft Preparation, X. Z. (Xiao Zhang), N. G. (Nan Gao), and S. Y. (Shuhong Yang) ; Writing Review and Editing, X. Z. (Xiao Zhang), N. G. (Nan Gao), S. Y. (Shuhong Yang), H. K. (Huma Khan) and W.Z. (Weiqiang Zhang) ; Supervision, W.Z. (Weiqiang Zhang); Project Administration, W.Z. (Weiqiang Zhang).

Funding: This research was funded by the grant from National Natural Science Foundation of China (21771122, 21571121), Key Research and Development Project of Shaanxi Science and Technology Department (2017SF-064).

Acknowledgments: This work was performed at the Xi'an Key Laboratory of Organometallic Material, Chemistry at Shaanxi Normal University, Xi'an, China.

Conflicts of Interest: The authors declare that there is no conflict of interests regarding the publication of the paper.

\section{References}

1. Selected Reviews of therapeutic application of CO and CO-RM: R. Motterlini; L. E. Otterbein. The therapeutic potential of carbon monoxide, Nat. Rev. Drug Discov. 2010, 9, 728-743; G. J. L. Bernardes. Carbon-Monoxide-Releasing Molecules for the Delivery of Therapeutic CO In Vivo. Angew. Chem. Int. Ed. 2014, 53, 9712-9721.

2. S. W. Ryter; J. Alam; A. M. K. Choi. Heme Oxygenase-1/Carbon Monoxide: From Basic Science to Therapeutic Applications. Physiol. Rev. 2006, 86, 583-650. 
3. H. J. Kim; Y. Joe; J. K. Yu; Y. Chen; S. O. Jeong; N. Mani; G. J. Cho; H. Pae; S. W. Ryterd; H. T. Chung. Carbon monoxide protects against hepatic ischemia/reperfusion injury by modulating the miR-34a/SIRT1 pathway. Biochim. Biophys. Acta 2015, $1550-1559$.

4. (a) Y. Wei; P. Chen; M. Bruyn; W. Zhang; E. Bremer; W. Helfrich. Carbon monoxide-Releasing Molecule-2 (CO-RM-2) attenuates acute hepatic ischemia reperfusion injury in rats. BMC Gastroenterol. 2010, 10, 42. (b) Y. Caumartin; J. Stephen; J. Deng; D. Lian; Z. Lan; W. Liu; B. Garcia; A. M. Jevnikar; H. Wang; G. Cepinskas; P. P. W. Luke. Kidney Int. 2011, 79, 1080-1089.

5. (a) R. Kretschmer; G. Gessner; H. Görls; S. H. Heinemann; M. Westerhausen. Dicarbonyl-bis(cysteamine)iron(II): A light induced carbon monoxide releasing molecule based on iron(CO-RM-S1). J. Inorg. Biochem., 2011, 6-9. (b) S. Romanski; B. Kraus; U. Schatzschneider; J. M. Neudörfl; S. Amslinger; H. G. Schmalz. Acyloxybutadiene Iron Tricarbonyl Complexes as Enzyme-Triggered CO-Releasing Molecules (ET-CO-RMs). Angew. Chem. Int. Ed. 2011, 50, 2392-2396.

6. J. P. Lomont, S. C. Nguyen, C. B. Harris, Organometallic 2014, 33, 6179-6185.

7. T. R. Johnson; B. E. Mann; I. P. Teasdale; H. Adams; R. Foresti; C. J. Green; R. Motterlini. Metal carbonyls as pharmaceuticals? $\left[\mathrm{Ru}(\mathrm{CO})_{3} \mathrm{Cl}\right.$ (glycinate)], a CO-Releasing molecule with an extensive aqueous solution chemistry. Dalton Trans. 2007, $1500-1508$.

8. J. D. Seixas; A. Mukhopadhyay; T. Santos-Silva; L. E. Otterbein; D. J. Gallo; S. S. Rodrigues; B. H. Guerreiro; A. M. L. Gonçalves; N. Penacho; A. R. Marques; A. C. Coelho; P. M. Reis; M. J. Romão; C. C. Romão. Characterization of a versatile organometallic pro-drug (CO-RM) for experimental CO based therapeutics. Dalton Trans. 2013, 42, 5985-5998.

9. H. T. Poh; B. T. Sim; T. S. Chwee; W. K. Leong; W. Y. Fan. The Dithiolate-Bridged Diiron Hexacarbonyl Complex Na2 $[(\mu-$ $\left.\left.\mathrm{SCH}_{2} \mathrm{CH}_{2} \mathrm{COO}\right) \mathrm{Fe}(\mathrm{CO})_{3}\right]_{2}$ as a Water-Soluble PhotoCO-RM. Organometallics 2014, 33, 959-963.

10. E. Kianfar; U. Monkowius; E. Portenkirchner; G. Knöer; Z. Naturforsch. Synthesis and Characterization of Novel $\operatorname{Re}(\mathrm{BIAN})(\mathrm{CO})(3) \mathrm{Cl}$ Derivatives Including the First Example of a Water-soluble Tricarbonyl Rhenium(I) Complex with Bis(imino)acenaphthene Ligands[J]. Z. Naturforsch. B 2014, 69, 691-598.

11. R. Mede; M. Klein; R. A. Claus; S. Krieck; S. Quickert; H. Görls; U. Neugebauer; M. Schmitt; G. Gessner; S. H. Heinemann; J. Popp; M. Bauer; M. Westerhausen. CO-RM-EDE1: A Highly Water-Soluble and Nontoxic Manganese-Based photoCO-RM with a Biogenic Ligand Sphere. Inorg. Chem. 2016, 55, 104-113.

12. W. Zhang; A. J. Atkin; I. J. S. Fairlamb; A. C. Whitwood; J. M. Lynam. Synthesis and Reactivity of Molybdenum Complexes Containing Functionalized Alkynyl Ligands: A Photochemically Activated CO-Releasing Molecule (PhotoCO-RM). Organometallics 2011, 30, 4643-4654.

13. A. R. Marques; L. Kromer; I. Bento; L. E. Otterbein; W. A. Blattler; C. C. Romao. Generation of Carbon Monoxide Releasing Molecules(CO-RMs) as Drug Can didates for the Treatment of Acute Liver Injury: Targeting of CO-RMs to the Liver. Organometallics 2012, 31, 16, 5810-5822

14. S. H. Crook; B. E. Mann; A. J. H. M. Meijer; H. Adams; P. Sawle; D. Scapens; R. Motterlini. $\left[\mathrm{Mn}(\mathrm{CO})_{4}\left\{\mathrm{~S}_{2} \mathrm{CNMe}(\mathrm{CH} 2 \mathrm{CO} 2 \mathrm{H})\right\}\right]$, a new water-soluble CO-releasing molecule. Dalton Trans. 2011, 40, 4230-4235.

15. A. E. Pierri; A. Pallaoro; G. Wu; P. C. Ford. A Luminescent and Biocompatible PhotoCO-RM. J. Am. Chem. Soc. 2012, 134, 1819718200.

16. U. Hasegawa; A. J. Vlies; E. Simeoni; C. Wandrey; J. A. Hubbell. Carbon Monoxide-Releasing Micelles for Immunotherapy. J. Am. Chem. Soc. 2010, 132, 18273-18280.

17. H. Pfeiffer; A. Rojas; J. Niesel; U. Schatzschneider. Sonogashira and "Click" reactions for the N-terminalandside-chain functionalization of peptides with $\left[\mathrm{Mn}(\mathrm{CO})_{3}(\mathrm{tpm})\right]^{+}$-based $\mathrm{CO}$ releasing molecules (tpm = tris(pyrazolyl)methane). Dalton Trans. 2009, 22, $4292-4298$.

18. F. Zobi; O. Blacque; A. Robert; J. Marcus; C. Schaubc; A. Y. Bogdanova. 17e- rhenium dicarbonyl CO-releasing molecules on a cobalamin scaffold for biological application. Dalton Trans. 2012, 41, 370.

19. P. Wang; H. Liu; Q. Zhao; Y. Chen; B. Liu; B. Zhang; Q. Zheng. Syntheses and evaluation of drug-like properties of CO-releasing molecules containing ruthenium and group 6 metal. Eur. J. Med. Chem. 2014, 74, 199-215.

20. H. Ringsdorf. Structure and properties of pharmacologically active polymers. J. Poly. Sci. 1975, 51, 135-153.

21. G. Pasut; M. Sergi; F. M. Veronese. Anti-cancer PEG-enzymes: 30 Years Old, but Still a Current Approach. Adv. Drug Deliv. Rev. 2008, 60, 69-78.

22. G.R. Crooks, B.F.G. Johnson, J. Lewis, I.G. Williams, G. Gamlen, Chemistry of polynuclear compounds. Part XVII. Some carboxylate complexes of ruthenium and osmium carbonyls J. Chem. Soc. A 1969, 2761-2766

23. B. Therrien; G. Suss-Fink. Sawhorse-type Diruthenium Tetracarbonyl Complexes, Coord. Chem. Rev. 2009, 253, 2639.

24. S. Yang, M. Chen, L. Zhou, G. Zhang, Z. Gao, W. Zhang. Photo-activated CO-releasing Molecules (PhotoCO-RMs) of Robust Sawhorse Scaffolds $\left[\mu_{2}-\mathrm{OOCR}^{1}, \eta^{1}-\mathrm{NH}_{2} \mathrm{CHR}^{2}(\mathrm{C}=\mathrm{O}] \mathrm{OCH}_{3}, \mathrm{Ru}(\mathrm{I})_{2} \mathrm{CO}_{4}\right]$. Dalton Trans. 2016, 45, 3727-3733.

25. A. Glomme, J. März, J. B. Dressman. Comparison of a Miniaturized Shake-Flask Solubility Method with Automated Potentiometric Acid/Base Titrations and Calculated Solubilities. J. Pharm. Sci. 2005, 94, 1-16. 